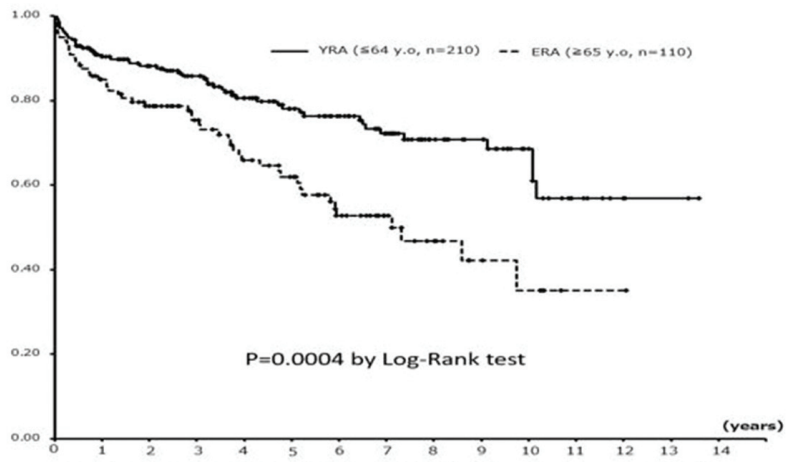

Figure 2 Continuation rate of biological therapy in YRA and ERA

YRA: younger RA patients, ERA: elderly RA patients

Conclusions: Although continuation rate of $\mathrm{BIO}$ treatment in ERA was inferior to that in YRA, that in $y E R A$ was not significantly different from that in oERA. Serious infection, especially in respiratory systems, was most frequent reason for stopping $\mathrm{BIO}$ therapy in ERA. These results suggested that BIO therapy in ERA demands close attention to infection and special strategies might need in the treatment of ERA people.

REFERENCE:

[1] Hirano Y, et al. Ann Rheum Dis 2015;74:700.

Disclosure of Interest: None declared DOI: 10.1136/annrheumdis-2018-eular.1654

\section{SAT0211 IS THERE A POTENTIAL FOR THERAPEUTIC DRUG MONITORING OF SUBCUTANEOUS TOCILIZUMAB IN PATIENTS WITH RHEUMATOID ARTHRITIS IN DAILY PRACTICE?}

Z. Layegh ${ }^{1}$, M. J. L 'Ami ${ }^{1}$, C. Bastida ${ }^{2}$, A. D. Huitema ${ }^{2,3}$, C. Krieckaert ${ }^{1}$, M. T. Nurmohamed ${ }^{1,4}$, T. Rispens 5 , G. Wolbink ${ }^{1,5} .{ }^{1}$ Amsterdam Rheumatology and immunology Center / Reade, ${ }^{2}$ Pharmacy\& Pharmacology, Cancer Institute-Antoni van Leeuwenhoek, Amsterdam, ${ }^{3}$ University Medical Center Utrecht, Utrecht, ${ }^{4}$ Amsterdam Rheumatology and Immunology Center I Vumc, university medical center, ${ }^{5}$ Immunopathology, Sanquin Research and Landsteiner Laboratory, Amsterdam, Netherlands

Background: Tocilizumab (TCZ), is a humanized antibody that competitively inhibits membrane-bound and soluble IL-6 receptors. Subcutaneous (sc) TCZ might be a potential candidate for therapeutic drug monitoring (TDM) since a high variability in serum concentrations has been reported. Considering that TCZ concentrations above $1 \mu \mathrm{g} / \mathrm{mL}$ have been claimed to be sufficient for normalizing CRP production (1), there might be an overexposure in a substantial proportion of patients. We expect that patients can at least reduce to a dose aiming for a trough concentration of $5 \mu \mathrm{g} / \mathrm{mL}$. Insights in serum concentrations of sc TCZ with clinical efficacy are lacking, but are necessary to reduce overexposure, potential dosedependent adverse effects and at the same time reduce costs.

Objectives: To describe TCZ trough serum concentrations in patients with rheumatoid arthritis (RA) treated with SC TCZ.

Methods: Prospective study with consecutive RA patients starting treatment with sc TCZ between June 2015 to October 2017 who had previously failed treatment with at least two DMARDs, including MTX. TCZ was administered at a dose of $162 \mathrm{mg}$ every week and patients were followed for 28 weeks. The study was conducted at the Amsterdam Rheumatology and Immunology Center| Reade. Serum trough samples were collected at baseline and at 4, 16, 28 weeks thereafter. An enzyme-linked immunosorbent assay (ELISA) was used for TCZ measurement. To analyze the concentration variability among patients at 28 weeks, a last observation carried forward approach was used.

Results: In total, 26 patients were included in the study and 94 TCZ serum concentrations were measured. Median and interquartile range (IQR) of the follow-up period was 28 (16-28) weeks and $54 \%$ of the patients accomplished week 28. Drug concentrations ranged from 0.2 to $63 \mu \mathrm{g} / \mathrm{mL}$, with an overall median (IQR) of $26,0(10,5-42,0) \mu \mathrm{g} / \mathrm{mL}$. In the majority of patients, TCZ concentrations stabilized after 4 weeks of treatment. Variability in drug concentrations at 28 weeks is shown in figure 1. Median (IQR) TCZ serum concentrations at 28 weeks was 24,0 (6.4$43,0) \mu \mathrm{g} / \mathrm{mL}, 92 \%$ of the patients achieved a concentration above $1 \mu \mathrm{g} / \mathrm{mL}$ and $88 \%$ had a concentration $>5 \mu \mathrm{g} / \mathrm{mL}$.
[TCZ] at 28 weeks with LOCF

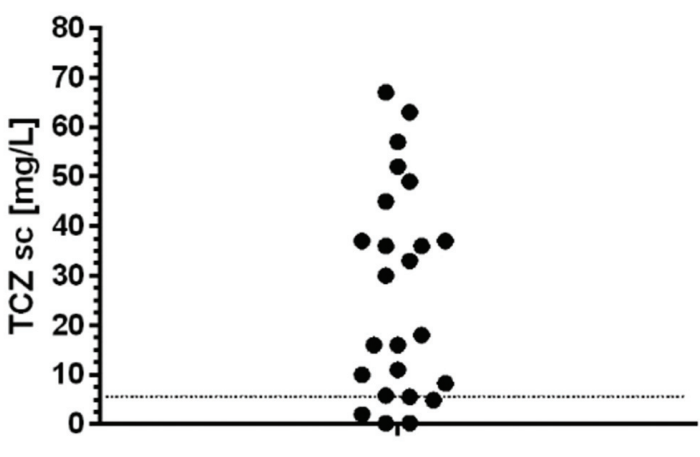

28 weeks

Conclusions: The Interindividual variability among patients on SC TCZ is remarkably high. The majority of the patients achieved serum concentrations far above $5 \mu \mathrm{g} / \mathrm{mL}$, suggesting overexposure in those patients. Therefore, TDM might be useful to optimize treatment, reduce (potential) side effects and achieve costeffectiveness.

\section{REFERENCE:}

[1] Br J. Clin Phamacol 2017 May;83(5):962-975.

Disclosure of Interest: Z. Layegh: None declared, M. L `Ami: None declared, C. Bastida: None declared, A. Huitema: None declared, C. Krieckaert Speakers bureau: Pfizer, M. Nurmohamed Grant/research support from: Pfizer, AbbVie, Roche, BMS, MSD, Mundipharma, UCB, Janssen, Menarini, Eli Lilly, Sanofi, and Celgene, Speakers bureau: Pfizer, AbbVie, Roche, BMS, MSD, Mundipharma, UCB, Janssen, Menarini, Eli Lilly, Sanofi, and Celgene, T. Rispens Grant/ research support from: Pfizer, Speakers bureau: Pfizer, UCB, AbbVie, Biogen, BMS, G. Wolbink Grant/research support from: Pfizer, Speakers bureau: Abbvie, UCB, BMS, Pfizer, Biogen

DOI: 10.1136/annrheumdis-2018-eular.6393

\section{SATURDAY, 16 JUNE 2018}

\section{Rheumatoid arthritis - non biologic treatment and small molecules}

\section{SAT0212 THE SAFETY AND TOLERABILITY OF INTRA- ARTICULAR INJECTION OF TOLEROGENIC DENDRITIC CELLS IN PATIENTS WITH RHEUMATOID ARTHRITIS: THE PRELIMINARY RESULTS}

Y. Kurochkina ${ }^{1}$, M. Tikhonova ${ }^{2}$, T. Tyrinova ${ }^{2}$, O. Leplina ${ }^{2}$, A. Sizikov ${ }^{1}$, A. Sulutian ${ }^{1}$, O. Chumasova ${ }^{1}$, A. Ostanin ${ }^{2}$, E. Chernykh ${ }^{2} .{ }^{1}$ Rheumatology, ${ }^{2}$ Cellular immunotherapy laboratory, Federal State Budgetary Scientific Institution Research Institute Of Fundamental And Clinical Immunology, Novosibirsk, Russian Federation

Background: Dendritic cells (DCs) are known to contribute to the pathogenesis of rheumatoid arthritis (RA) through the presentation of cartilage glycoprotein, production of proinflammatory cytokines and activation of Th1/Th17 responses. Along with stimulating activity, DCs may exhibit suppressive functions via capacity to induce $T$ cell apoptosis/anergy and to generate regulatory $T$ cells. Since these DCs have potential to control autoreactive T-lymphocytes, utilization of tolerogenic DCs seems to be a promising immunotherapeutic toolto treat RA.

Objectives: The aim of our study is to evaluate the safety and tolerability of a single intra-articular injection (into the knee joint) of autologous monocyte-derived dendritic cells generated in the presence of IFN- $\alpha / G M-C S F$ and tolerized with Dexamethasone in RA patients.

Methods: DCs were generated by culturing blood monocytes for 5 days with GM-CSF and IFN- $\alpha$ in the presence dexamethasone, applied on third day. Azoximer bromide as maturation stimuli was added on fourth day. Ten RA patients with moderate and high disease activity and ultrasound-defined knee synovitis were recruited in this study. All patients fullfield ACR/EULAR criteria (2010) and received methotrexate, leflunomide, sulfasalazine or their combination. The patients received intra-articular injections of $1^{*} 10^{6}, 3^{*} 10^{6}, 5^{*} 10^{6}, 8^{*} 10^{6} \mathrm{DCs}$ in knee joints. Safety was assessed by evaluation of adverse events (AE). Acceptability was assessed by questionnaire. DAS28 and HAQ were used for assessment of treatment efficiency. This trial registered on clinicaltrials.gov (ID: NCT03337165). 